\title{
Work in Britain's Informal Economy: Learning from Road-Side Hand Car Washes (10,000 Words)
}

\begin{abstract}
The UK has over 10,000 Hand Car Washes (HCWs). This article examines two research questions; what do HCWs reveal about the informalization of employment? and what is the prospect of regulation of them? Setting HCWs in a theoretical framework shows that they are part of a growing industry It is becoming an increasingly familiar and visible part of the economy, and is able to use informalization in employment where control of labour costs is a key factor. Employers make a strategic choice to engage precarious and vulnerable usually migrant labour securing further competitive advantage at the cost of pronounced labour exploitation and long hours - the tendency towards informalization. Therein a low-cost business model disciplines competition to usurp higher productivity mechanized car washing.
\end{abstract}

\section{Introduction}

In 2004 there were virtually no road-side hand-car washes (HCWs) in the UK. By 2013

estimates suggest the presence of 10,000 'informal' road-side hand car wash sites, approximately 3000 more than in the 'formal' car wash sector, (CWA, 2014).

\section{- How Did We Get Here?}

Hand car washing is a growing industry where informal employment practice and associated control of capital and labour costs appear as key factors. Accordingly the contribution this article makes is to examine two research questions; firstly, what do HCWs tell us about the informalization of employment in the UK? Secondly what regulatory challenges do HCWs pose for statutory and voluntary regulation of them?

To address these questions the article divides into three parts. Part one positions HCWs within a theoretical framework for informalization in employment. We embed this framework in the established literature on the connection between the formal and informal economy where re-structuring in the former has generated opportunities in the latter. More specifically our framework and its application to HCWs enables us to contribute to debates on the presence of migrant labour in low-skill precarious work. Many authors locate this within a 
social revolution comprising economic re-structuring, the diffusion of neo-liberalism and the emergence of finance-led capitalism designed to restore the power of elite interests in the UK by de-regulation and privatization (Harvey 2007, Cox and Nilsen, 2014:136). However, there is less explicit discussion of how these developments create transmission mechanisms that produce employment relations outcomes at firm level in the formal economy, the informal economy or the relationship between them. To remedy this gap the second part of the article traces the space occupied by newly emergent employers in road-side HCWs where there is little history of employment practice. This absence enables us to contrast cost-minimization strategies which inform much precarious informal work with the 'good worker' rhetoric associated with superficial explanations of employer preferences for migrant labour exposed by other authors; that they are cheap and work hard (Rodŕiguez, 2004, MacKenzie and Forde, 2009). We do so by establishing our contribution more firmly in the extant literature on employer strategies for the use of precarious often migrant labour in the informal economy and the more limited literature on HCWs. We also position the emergence of HCWs in contemporary approaches to economic re-structuring focused on 'post-capitalism' and the tension between automation and casualized low-paid work. In the third part of the article we detail our research method and our findings on HCWs. We then complete the article with a discussion of our research questions and follow this with a conclusion.

\section{1, The Tendency to Informalization in Employment.}

To substantiate our argument that HCWs are located at the intersection between the formal and informal economy we provide a framework to understand the tendency to informalization in employment relations. The informal economy is defined as paid activities that are unregulated by, or hidden from the state for tax, social security and or employment law purposes but are otherwise lawful (Williams, 2006, 2014). 
The informalization of employment relations can occur in four ways. Firstly, a business may be formally constituted but utilize forms of employment practice which are precarious (Standing, 2014). This occurs through the use of zero hours contracts and other forms of casualization (Adams and Deakin, 2014), use of agency workers (Hoque et. al. 2008) and 'posted' migrant workers (Lillie, 2012, Caro, et.al. 2015) and questionable or false selfemployment status currently associated with the so-called 'gig' economy or platform capitalism (de Stefano, 2016, Srineck, 2017). Secondly, a business may be formally constituted but business and employment practice are informal where workers are paid cashin-hand or work for favours where employee collusion is a more subtle form of exploitation which by its very nature is hard to detect, for example, the payment of envelope wages. Here a portion of total remuneration is undeclared to taxation authorities and may be paid separately (Williams 2014). In the ethnic cuisine restaurant sector those employers who evade the national minimum wage and working time regulations often collaborate with compliant workers to create a negotiated collusion in the workplace (Ram et.al. 2007:330334). A third tendency to informalization occurs where a business is informal and employment practice is informal too, for example, market traders may fall into this category, as do 'car booters' (Church-Gibson and Bruzzi, 2013) and other 'pop-up' businesses such as HCWs which set-up near sports stadiums on match days or when music events take place.

A fourth tendency to informalization occurs where a business is lawful, for example, garment manufacturing or HCWs but employment practice is unlawful and criminal. A recent study of garment manufacturing found severe violations of the national minimum wage with many workers paid only $£ 3$ per hour when the legal minimum was $£ 6.50$. These violations exhibit criminal practice such as use of child labour, wilful breaches of workplace health and safety legislation, refusal to pay agreed wages and or overtime payments, confiscation of passports 
and a requirement to reside in premises owned by the employer (Hammer and Plugor, 2016, authors 1).

\section{The Growth and Diffusion of Hand Car Washes}

A national survey recently reported that in 2013 there were approximately 18,500 car washes in the UK covering the regulated and unregulated sectors where in 2013-2014 the estimated income of broadly defined informal HCWs was $£ 449,550,000$; nearly three times that of the regulated sector at $£ 158,929,750$ (Car wash association, CWA, 2014). 7000 or $38 \%$ of these were mechanized conveyor washes, rollover washes or high powered hand-held jet washes. The CWA claim that these washes constitute the formally regulated sector. If this is the case $60 \%$ of the market or over 10,000 operators constitute informal HCW operations which are divisible into four sub-groups. Firstly, approximately 280 trolley washes operate in supermarket car parks and city centre car parks. Another $600 \mathrm{HCW}$ s operate in redundant rollover bays and in the region of $2000 \mathrm{HCWs}$ operate on former petrol station forecourts. Lastly, 7,500 HCWs are located in closed or still open public house car parks, open petrol stations, former tyre provider outlets or waste ground. So the presence of HCWs has grown significantly from virtually none in 2004. Our research on two east midlands cities (Leicester and Nottingham) suggests that these figures whilst providing a framework may over estimate the number of HCWs provided as they are by a key stakeholder in the regulated sector (Clark and Colling, 2016).

\section{Where did The Space Occupied by Hand Car Washes Come From? - The Dynamics of Economic Re-Structuring.}

The consolidation of supermarkets into four brands and the diffusion of large supermarkets on retail parks often nearby motorway junctions in the 1990s saw these retailers move into alcohol and petrol retailing as licensing controls were de-regulated in each area. Supermarkets now drive competition in petrol retailing often as a loss leader, a drive which undercuts road-side petrol stations and motorway service stations. Supermarkets and 
hypermarkets operate $17 \%$ of retail sites in the UK but account for $44 \%$ of fuel sales. The oil company owned sector controls $20 \%$ of sites but only $23 \%$ of market share. There are 5,500 independent sites which have a 33\% share of the market (in 1966 there were 40,000 such dealers), (UK PIA, 2015:31-2). A smoking ban in workplaces and public places other than private members' clubs became complete in 2007 bucking the trend to de-regulation but further reinforced the effects of de-regulation in the alcohol market. Twice as much alcohol is now consumed in domestic homes rather than pubs and clubs and between 2007-2012 6,000 pubs closed as a result of the smoking ban (IAS, 2014).

In addition, developments of financialization in auto retailing and technological advances in engine and motor maintenance have reduced the number of garage forecourts on which HCWs can ply their trade. These innovations witness car buyers incentivized by (often subsidized) personal finance plans which include service packages resulting in the sale of more autos by manufacturer sponsored main dealers. The diffusion of computer box controls for service diagnostics make it more difficult for general purpose mechanics in local garages to secure service business for newer cars. So as with petrol stations, pubs and clubs smaller car dealerships and road side garage numbers are in decline as well; both have large car park areas suitable for HCWs as do large supermarket car parks where trolley wash businesses are in evidence.

\section{Employer Strategies and Informal Labour}

The established literature on informal working demonstrates the manner in which (often) migrant labour has come to populate particular areas of work, for example, agriculture, catering, cleaning, garment manufacturing, food processing and packaging, hospitality and retail work (Wills et.al. 2009). There are some detailed case studies on these areas, for example, on the re-shoring of garment manufacturing to the UK, migrant workers in 
London's hospitality sector and on cleaners at a London University (Hammer and Plugor, 2016, Alberti, 2015 and Lopes and Hall, 2015). Other studies focus on 'business case' strategies which hide employer efforts towards informalization and cost-minimization strategies through the rhetoric of the 'good worker' thesis which inevitably leads them to engage migrant labour (Mackenzie and Forde, 2009, Bloch and McKay, 2015). In the formal economy the trend towards precarious work flows from policies which privilege casualization, suppress wages and stimulate 'fiscalization' (a reliance on benefits to top-up low wage levels) in employment (Adams and Deakin, 2014). The emergence and spread of non-standard work - employment casualization - evident in the use of intermediate agencies, on-call or zero hours working is mirrored in the informal economy. As a form of informalization the trend to casualization can be protected in the formal economy however meekly whereas in informal employment workers subject to informalization are largely unprotected. By association the literature recognizes that migration provides employers with the opportunity to substitute migrant labour for indigenous labour in an effort to increase the presence of labour flexibility, particularly external flexibility. Therein employers both formal and we argue informal utilize agencies or other intermediaries to provide labour, rely on work for favours, and sustain involuntary fixed-term or otherwise part-time or on-call work. There is though an implicit focus is on the formal economy wherein migrant labour exhibits a greater experience of unemployment, a lesser knowledge of employment protection legislation and collective bargaining rendering such workers more docile and precarious with significant potential for exploitation (Raess and Burgoon, 2015).

Work in the informal economy is suffused with exploitation and risk and is often physically demanding (Holgate, 2005, Fitzgerald, 2007). Other risks include underpayment and wage theft, working time violations, poor health and safety practice, non-payment of tax and 
national insurance contributions, hidden charges for accommodation and travel, deprivation of liberty and in some cases forced labour and threatened/actual violence to person or family (Appelbaum et al 2005; Bernhardt et al 2008; Geddes et al 2013; Wilkinson et al 2010, Alberti, 2015, 2016 and Clark and Colling, 2016). There is also an enormous variation in the ability of actors, both employers and employees to 'manage' risk along a 'continuum of exploitation' (Skrivankova 2010). In turn the normalization of collusion and exploitation may encourage stakeholders in a sector to adjust their behaviour in the light of others (McAdams and Nadler, 2008).

Turning to HCWs - in the UK a literature barely exists. There is though sometimes prominent newspaper coverage of enforcement action, deportations and unpaid fines levied on HCWs. These reports though rarely mention employment conditions but instead sensationalist headlines highlight and proclaim the presence of modern slavery for example, the Sunday Times recently reported 'Drivers beware: Slaves Working at Car Washes' (2016). Other contributions position the emergence of HCWs as emblematic of the UKs productivity problem where an inefficient, labour-intensive business model represents a regression into a grey informal economy (Haynes, 2015).

In contrast to the UK the literature on car wash workers in the United States reflects the more extensive diffusion of HCWs in large American cities and focuses on the associated presence of 'counter-culture' approaches to remedy the exploitation of precarious labour. These focus on community organizing and direct links with local government and the academic community (see Adler et.al. 2014 for a comprehensive comparative summary of these developments). Here union strategies tune into the diffusion and the over representation of migrant labour in the informal economy going further than traditional organizing to focus on social justice and fairness beyond formal industrial relations. Hand car wash campaigning groups such as C-L-E-A-N - the Community Labour Enforcement Action Network - have 
operated in Los Angeles since 2008 building community based social commitments beyond the workplace to diffuse a relational culture which emphasises trust between members and the group (Tapia, et.al. 2014). Established by the car wash organizing committee of the US Steel Workers' Union CLEAN campaigns to secure the right to organize the car wash sector but operates within but more significantly beyond collective bargaining to enforce labour standards and highlight examples of non-compliance in wages, terms and conditions and health and safety (Narro 2007, 2009). In contrast to these approaches more traditional trade union campaigns in the UK and the USA exhibit bureaucratic and institutional instrumentalism focussed as they are on the likelihood of securing membership which unions then commit to servicing (Holgate, 2015b).

In California estimates suggest the presence of 1,500 HCWs employing 28,000 workers where a third of the units are unlicensed (OAG, 2012). In 2010 the AFL-CIO reported 10,000 car wash workers in LA county estimating that $27 \%$ of these were undocumented (AFL-CIO, 2010). In New York City car wash workers suffer some of the most exploitative labour practices, for example, state law fixes HCW wages at three dollars per hour below the state minimum wage where employers are expected to pass on customer tips to make-up the difference between the two. Hand Car Washes remain however largely unregulated where wage theft from precarious often migrant labour is now the norm (Cullinane, 2016). Theodore et.al. (2012:210-214) track labour standards in low-wage employment in New York City, Chicago and Los Angeles and report significant wage theft violations from car wash workers where a third of workers in the sector are paid less than the legal minimum wage for tipped workers, many suffering underpayment of more than $\$ 1$ per hour where wage theft by employers translates into $15 \%$ of earnings. Efforts to organize car washes are problematic 
even in the presence of counter-culture approaches; New York City has $5000 \mathrm{HCW}$ workers in 200 outlets with 130 different owners averaging fewer than 30 workers on each site.

The absence of regulatory recourse is so extensive in HCWs, nail bars and restaurants that in New York City violations of employment and labour laws constitute the dominant business strategy. Despite these challenges W-A-S-H, (2012) -Workers Aligned for a Sustainable and Healthy New York - campaigns against wage and working time theft and unprotected exposure to hazardous chemicals suffered by the $10 \%$ of New York's HCW workers employed by one large employer, sometimes dubbed the 'Car Wash Kingpin' (Centre for Popular Democracy, 2013). W-A-S-H moved beyond the traditional union organizing model to expose business contracts between these car washes and the New York Police Department and other City agencies which led the City Mayor to end such contracts and many HCWs in the City have now signed union contracts. This successful formalization of informal employment relations in HCWs has however secured little further success beyond New York.

The spread of HCWs is also interesting in the context of the popularity of contemporary arguments about automation. Theoretically automation can bring about the permanent elimination of huge swathes of boring and demeaning work and make obsolete established social relations at work which centre on long hours and long commuting, developments which the advocates of automation encourage (Srnicek and Williams, 2015). We don't want to pre-empt our research findings but even at this point in the article it is clear that the emergence of HCWs demonstrates technology displacement by labour. Therefore the interesting question in relation to the automation thesis and its associated inclusions such as 
universal basic income is why labour deepening is present in this sector which reverses capital deepening?

\section{3, Researching Employment Relations in Hand Car Washes}

Firmly establishing our contribution against the background literatures of employer strategies on informal labour, HCWs and the contemporary automation thesis further informs our research questions on labour composition in HCWs and the wider political economy which surrounds HCWs. To report on this empirically we first detail how we conducted our research, then summarise our research findings and then draw out how we understand informalization and the regulatory responses to it from the state, trade unions and other stakeholders.

\section{Researching HCWs}

We have already noted that researching HCWs poses significant practical and ethical challenges and bearing these in mind we followed the lead of others and deployed flexibility in approach and opportunism in methodology during our fieldwork. In particular we like Bernhardt, et.al. (2008) recognise that workers in unregulated employment are vulnerable but in contrast to them we found that $\mathrm{HCW}$ workers and some $\mathrm{HCW}$ employers were prepared to discuss 'violations' of employment laws and environmental regulations. Further still we found formulating questions about workplace practices in HCWs difficult to construct and we also found many of the responses from workers difficult to codify. Our difficulties arose because of the different starting points and frames of reference which we as researchers held in contrast to those in the informal economy, for example, HCW workers may choose to operate in the informal economy or may be confined to it for other reasons such as migration status. Academic work within the informal economy is always likely to be affected by those conducting the work who have citizenship and access to employment rights whereas those 
being worked with do not and may not recognize the imperative of formalized research practices formulated in the academic community (see Rodŕiguez, 2007, 2004:152-156).

To overcome these difficulties our research method contained four elements. Firstly, we set out to map, categorise and codify HCW sites in two cities in the East Midlands. The categorisation of HCWs divided them into permanent or pop-up sites whereas the coding process related to types of HCW (trolley washes, those based in, at or near still open petrol stations, those located on former petrol station car parks and those located on pub car parks). We commenced this work in April 2014 and completed the mapping and categorization of HCWs reported on this article in June 2016. Within the two City boundaries we found 20 permanent HCWs in one city and 26 in a second city. Twenty of these were operating on former petrol station forecourts where we secured interviews at ten sites; we found three trolley washes in the car parks of national brand supermarkets and secured interviews at two of these sites. We mapped ten car washes in former pub car parks and secured interviews with a worker from five of these sites. We found three HCWs operating on waste ground in alleys adjacent to open petrol stations and interviewed workers from two sites. We also found ten HCWs operating on still open national brand petrol stations alongside still working or redundant mechanized car wash units where we interviewed workers from five of these sites. We spoke to more than twenty four workers as some interviewees were accompanied by a colleague and at other times whilst we interviewed one worker others were close by. Our conversational approach made it impractical to record these encounters. Most participants asked us not to do so and as these interviews took place in cafés, whilst walking with interviewees after work or in pubs or at bus stops the environment was unsuitable to do so. In addition we chose to discount other interviews and conversations with workers at 'pop-up' HCWs precisely because of their itinerant nature and we discounted other 'dead-ended' 
interviews at HCWs in our totals but used both sources to provide further context to the study.

The HCWs we report on are broadly representative of the sites in the two cities but exclude trolley washes in the car parks of two city centre shopping centres from which we were denied access. The itinerant and transitory nature of some HCWs combined with the 'pop-up' status of others renders the creation of a statistically representative sample implausible, rather than this our study reports on a mix of HCW sites and sector stakeholders. Similar to other studies of precarious communal based regulation (McDowell, et.al. 2014) this enables us to report on social processes (in our case informalization) and the manner in which the broader political economy of employment regulation in the UK enables and facilitates the formation of a distinct group - HCWs. Therefore our study produces findings which are detailed and context-dependent (Flybjerg, 2006).

The second element again followed the lead of other researchers. We undertook 'participatory' research (Alberti, 2015) by using HCWs, direct observation of them and engaging $\mathrm{HCW}$ workers in conversation. This led to initial interview contacts, in turn these led to referral or 'snowball' contacts which is a proven method utilized in researching difficult to access work groups (Hagen, 2011, et.al.). A form of non-probability sampling snowballing leads established research contacts to generate further contacts from friendship groups and work groups either directly or by association.

The third element saw us conduct more recognizable semi-structured interviews with sector stakeholders some of whom have a regulatory role in the sector such as the Gang Masters Labour and Abuse authority where we conducted five detailed interviews. We conducted two interviews with the commercial manager of the Petrol Retailer's Association and held one interview each with the deputy chairman of the Car Wash Association and the CEO of a 
nationally recognized supplier of car wash equipment and materials. We interviewed local authority regulators from cities in the midlands - those which we had mapped and those in an adjacent city. We held one-off telephone interviews with the immigration enforcement section of the Home Office, the Environment Agency and an enforcement officer at a national water company. These more formal interviews were transcribed whereas notes were made during telephone calls which were then written-up more formally immediately afterwards. The final element in our research strategy centred on desk research which analysed fifty documents relating to regulation, regulation of regulators, government consultation and responses to consultation on what we term a new regulatory infrastructure.

In total we secured forty-six interviews which provide empirical support for our focus on the construction and regulation of HCWs which employ labour informally; twenty four interviews at HCWs; nine full interviews with sector stakeholders and eleven partial what we termed 'dead-ended' interviews. Dead-ended interviews are those where access and informed consent was secured but was suddenly terminated. This happened to us at the Home Office, a nationally known supermarket and at a water company. These terminations are methodologically significant contextual factors in the political economy of informalization where these contacts preferred to avoid probing questions. When pressed about regulatory compliance we received responses such as 'we don't want to get into this' 'before we answer you need to provide us with full details of your research sites' and 'all on-site contractors are assumed to be compliant'. We have chosen not to attribute some of these quotes to those who originated them yet the tenor of them provides valuable context.

\section{What Did We Find?}

We report first on our findings from $\mathrm{HCW}$ sites and then report our findings from regulators, within these we suggest how HCWs operate at the intersection between the formal and informal economy. The sensitivity of our research findings requires us to report them in 
abstract but open terms by which we mean in a manner which is not attributable to named individuals or particular workplaces. For example we build a composite response from interviewees to provide context on why informalization and use of migrant labour is the norm in informal HCWs.

\section{Why is Informalization the Norm in HCWs?}

The responses we received about migrant working as the norm in HCWs suggested that unskilled migrants have limited options; they can work in catering, either ethnic restaurants or food preparation or processing, in ethnic supermarkets, in construction, in households, the sex industry or can gravitate towards other businesses or subsistence operations dominated by workers from their own or a nearby country of origin. HCW owner workers suggested to us that there are many websites explaining how to set up informal HCWs, where to contact intermediaries and secure labour and how to manage relations with the formal economy, that is breweries, petrol station owners and supermarkets (who act as landlords) and how to source water and secure an electricity provider. Some owners and workers suggested more sinister explanations where HCWs acted as diffusion mechanisms for undocumented migrants, where forms of forced labour or even slavery operate. No doubt these forms do exist but we found none of these, for example, we established that no workers slept on-site in containers or cashier areas at the HCWs which we surveyed. We did though establish that some workers lived in dormitory accommodation provided by their employers. The majority of $\mathrm{HCW}$ workers we interviewed stated that they gravitated to car washes because they could easily get work there and that it was well-known that HCWs are in the main run by migrants for migrants and that British workers wouldn't do the work even if a car wash was British owned. Many accepted exploitation in their current employment to get a start in work and within a local community. So in terms of the rhetoric of the 'good worker' thesis there is in HCWs no clear-cut business case for the engagement of migrants rather than non-migrant 
labour; migrants are selected precisely because they are cheap and accept informal employment practice. There is no evidence to suggest that they are more motivated or that they work harder than non-migrants. Instead a mixed set of socio-economic realities motivate the engagement of migrants and associated mixed realities why migrants choose to work at HCWs; these are though informed by the presence of migrant employers diffused across the HCW sector.

Across the 46 sites we categorized and surveyed we found a clear-cut shift from capital intensity to labour intensity, foregoing technology that was designed to replace hand car washing, that is, we found not capital deepening which makes the economy more productive but perversely capital shallowing. We witnessed expensive jet and rollover washes lying idle whilst customers queued for a hand car wash. During the course of our field work an unexpected finding relating to the status of some car washes became evident. Initially we viewed all those we surveyed as businesses, however, at some locations (those operating on former pub car parks, in alleys adjacent to open petrol stations and most pop-ups) both workers and owners reported them as subsistence operations. Further still at these and more regular HCW businesses both owners and workers argued that 'their' $\mathrm{HCW}$ was part of a country of origin extended network formed by family and kinship relations. It was clear to us that some car washes were subsistence operations whereas others claimed this status to deny that employment practices were informalized. Therefore the more basic car washes, for example, those located on waste ground and five of those operating on pub car parks (three of which where we conducted interviews) are more appropriately characterised as subsistence forms. The three sites which operated on waste ground washed cars traditionally, that is without the use of jet sprays using instead sponges and 'shammy' leathers to dry cars. These HCWs were not mains connected and used cold water which they brought with them in plastic containers or in one case which they sourced from garden hoses from nearby 
dwellings. Similarly, one of the HCWs operating on a former petrol station forecourt had no mains water and its electricity supply was sourced from an ethnic minority supermarket next door. Reminiscent of arguments developed by Williams and Windebank, (2002:244-5) the social relations and motives in paid informal exchange at some HCWs is not market-like based on employment and economic gain but alternative social relations embedded in kinship and re-distribution to communities in the migrant workers' country of origin.

One way that HCWs operate at the intersection of the formal economy is in their status as registered businesses which hold a lease to run a business on a property; we found that most had mains electricity though the three sites which we describe as subsistence operations did not appear to be legitimate businesses and one ran electricity for car hoovers via extension cables from a domestic dwelling. Most sites were rented but three were operator owned, it was unclear who owned the waste ground where some subsistence operations were based. All sites appeared to operate as single site establishments and were not part of a branded chain; however, one owner-worker listed three HCW sites he owned in one of the two cities - our observations and participatory method confirmed this was the case. Across both cities regulatory capture is permissive; employment, environmental, electrical, plumbing, water and ground works regulations are minimal and often not enforced. Informalization of employment also creates the potential for hidden externalities such as the growth of unrecorded employee and customer accidents and injuries and damage to cars caused by very small stones and grit in 'shammy' leathers. In addition health and safety standards appeared to be poor both for workers and the immediate environment surrounding a car wash, for example heavier chemical solutions were discharged down regular storm drains which degraded tarmac and nearby pavement edges. 
In employment relations we found widespread denial of employment status, avoidance of the minimum wage, and working time regulations. Our efforts to discuss wages and terms and conditions proved difficult in all interviews and sometimes resulted in termination of the interview or aggressive responses. Eight interviewees across three forms of HCW (excluding trolley washes) stated that their wages were less than the national minimum wage rate (which we provided to them as a list). We found that car wash workers at former petrol stations and former pub car parks which were not subsistence operations earned $£ 50$ for a 9 hour day (including sustained periods of down-time). For more than half our twenty-four interviewees this was topped up by housing benefit some of which paid for accommodation. Our calculations suggested that typical underpayment for these workers was around $£ 42$ per week; approximately $14 \%$ or 91 pence per hour had they received the then adult minimum wage of $£ 6.50$.

Trolley washes on supermarket car parks represent a second intersection with the formal economy. These appeared as professional providers where operatives had professionally manufactured equipment trolleys and wore liveried uniforms, high visibility jackets and waterproofs. Supermarket trolley washes have three or four members per team who work in competition with other teams on the same car park where team members approach shoppers as they park and hawk for work. Typical of this at one large supermarket car park we found four teams of three workers operating across 725 spaces, approximately 181 spaces per team. The three trolley wash teams who operated in supermarket car parks earned more than those in more typical roadside HCWs and we observed them over an hour securing five wash deals at $£ 6$ per wash. Trolley wash workers considered themselves to be less exploited because they view themselves as self-employed. For purposes of comparison if we assume that the three or four person teams are really employees $£ 30$ per hour is $£ 10$ per hour for three person teams and $£ 7.50$ per hour for four person teams. These numbers do represent a significant 
mark-up on roadside HCW remuneration and take trolley wash workers between $53 \%$ and $15 \%$ above the then hourly national minimum wage of $£ 6.50$. However, the figures require qualification. Firstly, the work on supermarket car parks is less consistent than in many roadside HCWs and is affected by weather conditions because most trolley washes operate in the open air. Trolley wash workers are not present in supermarket car parks all day or every day, accordingly the hourly payment number that we estimated on the basis of our observations and interviews are unlikely to be as good every day. Secondly, due to 'dead-ending' we were unable to secure information on what rental trolley wash teams paid to rent the trolley equipment or intermediaries who secured the sub-contract from the supermarket. The supermarket manager also declined to discuss this issue with us. So it is likely that an unknown amount of money has to be deducted from the hourly revenue numbers.

Whilst employment practice and employment relations are informal in HCWs we found that beyond subsistence operations a third intersection with the formal economy was the formality of business presentation. On many sites signage was clear and presented professionally mimicking signage in regulated mechanized car washes and those located on oil company owned outlets (BP, Esso and Shell). Similarly some sites had professionally manufacturing rolled steel awnings, they also cited visa and master card payment however we found that all 46 sites were cash only businesses which provide two types of service; outside washes or an outside wash and an inside clean. Some workers wore protective gloves and footwear which was often liveried but this was not universally the case. At road-side HCWs (but not car park trolley washes or subsistence operations) typically a team leader controlled the pace of work, the pressurized water jet and directed customers on the basis of either a full (inside and outside) or outside service. In addition an overseer manages customer takings where individual operatives ask for change for customers if necessary, handing over the money to the overseer. Any tips were also given to the overseer. 
We found that work organization was not amateur or dis-organized but highly structured and standardized both within and across sites, punctuated by scripted speech (inside or outside service) and simple and technical controls, for example queueing systems where preparatory detergent spraying was undertaken. At road-side HCWs operatives multi-task in informal teams under the direction of a designated team leader. We interviewed workers who previously worked professionally as hairdressers, front of house hotel staff and teachers in their country of origin and found that these workers accepted employment at a HCW despite it being '3-D' work; dirty, dangerous and degrading (Rodriguez, 2007:5). They did so to adjust to a new environment and improve their English but like migrant workers in other sectors HCW workers used informal networks to promote job mobility and help build skills to escape this work (Alberti, 2015, Hagan et.al. 2011). These networks were of two types; coethnic social networks which flowed from country of origin connections and those forged by co-ethnic workers or social networks created by migrant workers across nationality groups (for more detail on this distinction see Batnitzky and McDowell, 2013:1998-1999). In contrast to this we also found 'alone movers' (Caro et. al. 2015:1602) with little or no English and few or no qualifications and no vocational skills who relied on intermediaries to secure jobs. So there are different types of migrant labour employed in HCWs. Some are reliant on intermediaries and wider social networks for employment which can confine precarious workers to less good jobs in either formal or informal employment (Williams, 2009, McCollum and Findlay, 2015:430). We found that a permissive UK legal environment created a 'sub-contract' labour market populated by precarious and vulnerable labour unsure if they are an employee and who may not know the identity of their employer (Wills et. al. 2009). Within our sample we found no evidence of counter-movement community based organizing and we found only two local state campaigns (in Coventry and Luton) designed to 
secure effective regulation of HCWs are in evidence (authors 2). The absence of community organizations which operate beyond traditional bargaining structures similar to those of CLEAN and WASH, highlighted in US research, contribute to the widespread absence of pressure on employers, policy makers and local or national state managers (Givan, 2007, Tapia, 2013).

\section{The Potential for Regulation of Hand Car Washes?}

Turning to the regulation of HCWs our interviews at the Gang masters and Labour Abuse Authority (GLAA) combined with our documentary research revealed to us a tension between what we term 'the entrepreneurial approach' of GLAA regulators and 'regulation of the regulators'. On the former we found GLAA employees had a purposeful 'detective' approach to their tasks and that GLAA staff are proactive rather than compliant in establishing new networks with labour inspectorates across the EU. This approach is informed by the police and military backgrounds of many GLAA inspectors and the 'Policestyle' powers the GLAA possesses to ensure that investigations meet the necessary evidential standards for criminal prosecution. These powers are impressive and in operation and practice we found that GLAA staff operated in a distinctive and active manner focussed on effective intelligence gathering.

In the UK labour market enforcement is co-ordinated across three agencies; the GLAA, the Employment Agencies Inspectorate and Her Majesty’s Revenue and Customs for enforcement of the national minimum wage. The Modern Slavery Act 2015 and the Immigration Act 2016 develop a potentially powerful criminal code to deal with the most serious forms of labour market exploitation with a particular focus on protection for those subject to exploitation. However, regulators such as the GLAA and the Low Pay Commission are themselves subject to regulation - 'regulating the regulators'. The 2005 Hampton review 
argued that the UK regulatory system imposes too many duplicate forms of regulation on employers and recommended reducing inspections by a third meaning around one million fewer inspectors across the system. Further still the Regulator's Code imposes a framework on regulators on how they engage with those whom they regulate. Similarly, sections 108-9 the Deregulation Act 2015 impose a duty on regulators to have regard in the delivery of their work for the desirability and importance of promoting economic growth and ensuring that regulatory action is proportionate and only taken when necessary. Finally, the Enterprise Act 2016 eases the regulatory burden on small businesses and further requires regulators such as the GLAA and HRMC to report how they meet their duties set out in the growth duty and the regulator's code. Both require regulators to include the views of business in their report.

The regulatory centrepiece is the GLAA which revitalises and extends the Gang masters Licensing Authority (GLA). The GLA was established by Gang masters (Licensing) Act 2004 to investigate four offences, operating as an unlicensed gang master; possessing a false document for the purpose of deceiving others regarding whether they are licensed; entering into arrangements with an unlicensed gang master and obstructing GLA officers in their duties. The remit of GLAA will soon cover the whole economy potentially creating a labour inspectorate where a new enforcement order will address serious breaches of labour law by inviting a business to undertake to eliminate breaches. Enforcement Orders are available on application to a court where non-compliance with an enforcement order constitutes a criminal offence attracting a custodial sentence.

We found that the GLAA commands respect from labour intermediaries; from those that head supply chains; from trade unions and from workers (with caveats). For example, the Modern Slavery Act applies to all commercial organizations with a global turnover greater than $£ 36$ million. This together with GLAA standard setting activity informed pressure from the 
USDAW trade union to persuade Tesco ban all independent HCWs from their car parks and replace these with Tesco HCWs where workers are directly employed by the supermarket and its subsidiaries. This development represents a further intersection between the formal and informal economy; whilst the evidence suggests that in the UK informal HCWs appear as the norm the presence of statutory and voluntary regulation has stimulated a large firm in the formal economy to squeeze out informality on its premises. This is though in in stark contrast to other landlords' and supermarkets where independent trolley washes operate on the basis that on-site contractors 'are compliant' (interview with supermarket manager).

Another case revealed to us in our interviews illustrates the nature of entrepreneurial approach of GLAA staff. GLAA inspectors working on a case were told by an employer that Bulgarian workers under examination were not liable to be paid the national minimum wage as they were employed locally in Bulgaria and 'posted' to the UK on a temporary basis. The GLAA inspectors reported this to the then department of Business, Innovation and Skills who were satisfied with this response. Bearing in mind the detective backgrounds of many of those employed in the GLAA the reaction of GLAA inspectors was not surprising. They doubted that the workers were actually posted and contacted the Bulgarian Labour inspectorate directly and passed on details of the case and the labour market intermediaries involved in posting the workers. Two weeks later they were told that the intermediaries were not registered and the workers were not employed locally in Bulgaria or posted to the UK. The GLAA pursued the case and found that the workers were recruited in the UK and then prosecuted the UK employer and secured back payment of stolen wages for the workers. Hence it is clear that in the formulation of the contemporary legislative and regulatory framework a tension exists between the department of Business, Energy, Innovation and Skills and the GLAA where the latter is not content with compliance based on the testimony of the parties to a case. These findings lead us to suggest that what we term the 
entrepreneurial approach of the GLAA actually swims against the tide of de-regulation and re-structuring.

We found the permissive regulatory environment maintained by local authorities and private sector bodies such as water companies, landlords, supermarkets and consumers make it unlikely that many HCWs will be challenged by these bodies. In one interview with a water company when discussion of imposition and collection of water rates was raised the response we received was 'we don't want to get into this' (interview notes) and we have already mentioned the response of a supermarket manager on trolley washes which assumed all onsite contractors are compliant. It appeared to us that the hand car washes we surveyed and the HCW workers and owners we interviewed are both clearly visible and less visible at the same time; visible at the road-side and in terms of embeddedness and familiarity but less visible in terms of regulatory enforcement.

\section{Discussion and Conclusion}

In terms of our first research question, both generally and specifically in HCWs, informalization is part of the economic re-structuring described by other authors where it is a proxy for de-regulation, flexibility and innovation but on the backs of labour. The tendency to informalization described in this article is indicative of the first tendency in our framework to informalization which suppresses wages and privileges casualization. In the formal economy and unregulated areas such as HCWs a second tendency to informalization mediates the relationship between capital and labour where employers make a strategic choice to eschew core protections such as the national minimum wage, overtime payments, meal breaks and itemized wage slips. These derogations impose distributional, employment and environmental externalities on society in the forms of underpayments, wage theft, pollution and lost taxation revenue. It is the case for example, that hand car washing is a lawful 
activity, however, the tendency to informalization is manifest as a failure to observe both employment and environmental regulations where the intersection of the formal and informal economy to stimulate two developments. Firstly, many road-side HCWs, which are legitimate businesses choose to employ labour informally. It is also the case that legitimate businesses unwittingly or knowingly support a tendency to informalization in roles such as trade suppliers or landlords.

Similarly consumers support these businesses. Therefore a particular finding revealed by this study which is generalizable beyond HCWs is the theoretical and empirical necessity to move beyond a simple formal economy/informal economy dichotomy. The two are not separate entities but intimately connected where outlets in the informal economy help re-production of sectors in the formal economy, for example, established business landlords be they supermarkets, breweries or oil companies which own former pub and petrol station sites are able to extract revenue from their assets. This is particularly the case for supermarkets and road-side HCWs which are under heavy competitive pressures from new smaller supermarket entrants and supermarket petrol stations. It is here that the symbiotic relationship between established and informal businesses is evident. A second development which is likely to have a direct impact on the growth of HCWs is the globalization of labour supplies in many cities in the UK (Wills et.al. 2009). This generates a new migrant division of labour sometimes termed 'super-diversity' (Ram et.al. 2011). Super-diversity combines with contemporary forms of de-regulation such as sub-contracting and outsourcing which under neo-liberalism reduce wages and erode established conditions of employment in the formal economy, reductions which are also re-produced in less formal areas of employment. Again the tendency to informalization in the formal economy is re-produced and extended in the informal economy but unlawfully. Accordingly, it is likely that employment relations practices in HCWs indicative of the third and fourth tendency to informalization in our 
framework are not just that; rather they have some origins in the formal economy. However, the tendency to informalized unlawful employment practice in cases such as HCWs also represents a form of subcontract capitalism connecting developments in the informal economy to those in the formal economy where employers exhibit a preference to employ precarious and vulnerable workers - a so-called precariat (Standing, 2014:176). This preference is a key challenge in the enforcement of employment regulations - identifying informality in employment and identifying actors and agencies which have statutory and voluntary regulatory capture to remedy the situation.

In part these challenges derived from economic re-structuring grounded in the reconfiguration of retailing, alcohol consumption and auto sales which has released land suitable for permanent or pop-up HCWs. Re-structuring combines with the demise of established regulatory frameworks such as collective bargaining and the marginalization of individual employment rights. Each of the latter focussed on the de-commodification of labour and are rendered less potent by the operational logic of informal working and associated pressures which lead to low productivity, low-value marginal sectors such as HCWs. So we agree with the conclusions of Raess and Burgoon (2015) that employers in the formal and informal economy who have a preference to employ migrant labour do so to stimulate low cost flexibility. In addition to this we argue that the emergence of road-side HCWs which are populated by migrant labour neither complement nor substitute for indigenous worker profiles. This leads us to our second research question on regulation and the role of the UKs political economy and institutional framework in the construction, diffusion and regulation of new areas of informal employment such as HCWs. Here there is much to discuss. 
We surveyed $46 \mathrm{HCWs}$ the majority of which we characterise as based on the employment relationship however informal where most sites fitted our second characterization of the tendency to informalization; lawful businesses utilizing unlawful employment relations and environmental practices. We discerned that there were 40 ownership forms (one owner owned three of the HCWs) including some not necessarily indicative of economic exchange relations but subsistence relations. The atomization of ownership across HCWs in the two cities makes traditional union organizing drives or counter-movement approaches developed in the USA very resource intensive as employers are difficult to identify and make a strategic choice to utilize a business model which rests on paying workers less than the minimum wage. We found no union presence and as a result of this, trade union organizing drives have to take on the burden of a sector wide approach to improved wage enforcement across a city. In contradistinction to this we found that most pressure both nationally and locally was put on national supermarkets by the USDAW trade union. This pressure took the form of persuading Tesco to ban HCWs from property they owned which was earmarked for the development of smaller local supermarkets or from car parks in already established larger out of town supermarkets. None the less in the UK the enmity between trade unions and community based organizations appear to further marginalize successes in traditional union organizing (Holgate, 2015a\&b). It follows from this that counter-culture approaches to organizing HCWs developed in the United States are more imperative than ever but are unlikely to develop in the UK as unions concentrate resources on the formal economy (see also Alberti, 2016). Our study demonstrates that HCW employers are effectively insulated from the need to concede to regulatory compliance because any worker grievances are unlikely to be mobilised into activism, this is particularly likely in trolley washes and subsistence operations. 
HCWs are highly competitive and have very low entry costs where informal employment generates autonomous economic growth in the unregulated economy. Hence in both cities HCWs have the potential to become the established car wash sector compelling established mechanized outlets to an uncertain future as informality of business practice and employment practice in car washing becomes the norm. Our focus on the broader political economy enables us to position low-cost informal recruitment associated low pay and flexibility in marginal business survival within more universal capitalist processes that are informed by related economic re-structuring. These processes create economic and social marginalization and conflict bound exploitation in the employment relationship however informal and paternalistic it may appear to be in the form of 'wage and working time theft'.

In conclusion our findings on HCWs advance understanding of informalization reporting as they do a shift from capital intensity indicative of capital deepening to labour intensity and capital shallowing indicative of the UKs productivity problem. Capital deepening improves productivity and the skills set of labour whereas empirically in HCWs capital shallowing substitutes labour for capital because labour is so cheap. Here the spread and the visibility of HCWs result from a growing tolerance of informalization amongst the population, those with regulatory capture and more formal regulators too. Informalization is facilitated by the light touch frameworks in the UK's political economy of industrial relations which the entrepreneurial approach of the GLAA may fail to substantially reverse. Informalization sustains HCWs which are highly competitive, have low costs of entry, and are subject to environmental and employment regulation which appear permissive in terms of enforcement. Precarious and vulnerable evidently migrant labour provides a further competitive advantage but at the cost of pronounced labour exploitation and long hours - the tendency towards informalization. Employers make a strategic choice to take advantage of exploitative labour practices to gain competitive advantage over mechanized car washes which co-creates a new 
low-margin area of employment. Therein a low-cost business model disciplines competition to usurp higher productivity mechanized car washing.

\section{References:}

Adams, Z. and Deakin, S. (2014). Institutional Solutions to Precariousness and Inequality in Labour Markets British Journal of Industrial Relations 54(4) 779-809.

Adler, L., Tapia, M., Turner, L. (eds) (2014). Mobilizing Against Inequality: Unions, Immigrant Workers and the Crisis of Capitalism. Ithaca, Cornell University Press.

Alberti, G. (2016). Moving beyond the Dichotomy of Workplace and Community Unionism: The Challenges of Organizing Migrant Workers in London's Hotels Economic and Industrial Democracy 37(1) 73-94

Alberti, G. (2015). Mobility Strategies, "Mobility Differentials" and "Transnational Exit": The Experience of Precarious Migrants in London's Hospitality Sector Work, Employment and Society' 28(6) 865-882.

American Federation of Labour-Congress of Industrial Organizations (2010) The CLEAN Carwash Campaign AFL-CIO, April.

Appelbaum, E., Bernhardt, A., Murnane, R., Weinberg, J. (2005). 'Low-wage employment in America: results from a set of recent industry case studies' Socio-Economic Review, pp.293310 .

Batnitzky, A. and McDowell, L. (2012). 'The emergence of an "ethnic economy"? The spatial relationships of migrant workers in London's health and hospitality sectors' Ethnic and Racial Studies 36(12) 1997-2015.

Bernhardt A, McGrath S, and DeFilippis J. (2008). 'The state of worker protections in the United States: Unregulated Work in New York.' International Labour Review 147(2) 135162.

Bloch A, and McKay S, (2015). 'Employment, Social Networks and Undocumented Migrants: The Employer Perspective’ Sociology 49(1) 38-55.

Car Wash Association (2014). UK Hand Car Wash Market-Key Facts CWA, control publication for members only.

Caro, E., Berntsen, L., Lillie, N., Wagner, I. (2015). 'Posted Migration and Segregation in the European construction sector' Journal of Ethnic and Migration Studies 41(10) 1600-20.

The Centre for Popular Democracy - The Car Wash King Pin Report, (2013) Centre for Public Democracy report available to download at cpd@populardemocracy.org downloaded April $5^{\text {th }} 2016$.

Church-Gibson, P. and Bruzzi, S. (eds) (2013). Fashion Cultures Revisited: Theories, Explanations and Analysis. London, Routedge. 
Clark, I. and Colling, T. (2016) 'New Insights into Informal Migrant Employment: Hand Car Washes in a Mid-Sized English City’ Economic and Industrial Democracy. On-line first September $30^{\text {th }}$

Cox, L. and Nilsen, A. (2014). We Make Our Own History - Marxism and Social Movement in the Twilight of Neo-Liberalism, London, Verso.

Cullinane, S. (2016). “ "Carwasheros” Unionise New York City: Community-Labour Partnerships and the Challenges of Organizing a Runaway Industry'. The Global Labour Column http://coumn.global-labor-university.org/ downloaded May $3^{\text {rd }}$

de Stefano, V (2016). 'The rise of the just-in-time workforce: on-demand work, crowdwork and labour protection in the gig-economy' Geneva, ILO.

Fitzgerald, I. (2007). 'Working in the UK: Polish Worker Routes into Employment' London, TUC.

Flyvberg, B. (2006). 'Five Misunderstandings about Case-Study Research' Qualitative Inquiry 12(2) 219-245.

Geddes, A., Craig, G. \& Scott, S., (2013). Forced Labour in the UK, York, Joseph Rowntree Trust.

Givan, R. (2007). 'Side by Side we Battle Onward? Representing Workers in Contemporary America' British Journal of Industrial Relations 45(4) 829-55

Hagan J, Lowe, N. and Quingla, C. (2011). 'Skills on the Move: Re-Thinking the Relationship between Human Capital and Immigrant Labour Mobility' Work and Occupations 38(2) 149-178.

Hammer, N. and Plugor, R. (2016). 'Near-sourcing UK Apparel: Value Chain Re-structuring, Productivity, and the Informal Economy' Industrial Relations Journal 47(5) 402-416.

Harvey, D. (2007). A Brief History of Neo Liberalism, Oxford, Oxford University Press.

Haynes, M. (2015). 'The Return of the hand car wash and the UKs productivity puzzle' - The Conversation, April $7^{\text {th }}$ http://theconversation.com article downloaded April $10^{\text {th }} 2016$.

Holgate, J. (2005). 'Organizing Migrant Workers' Work, Employment and Society 19(1) 4680 .

Holgate, J. (2015a). 'Community Organizing in the UK: A "New Approach for Trade Unions' Economic and Industrial Democracy 36(3) 431-455

Holgate, J. (2015b). 'An International Study of Trade Union Involvement in Community Organizing: Same Model Different Outcomes’ British Journal of Industrial Relations 53(2) 460-483.

Hoque, K., Kirkpatrick, I., De Ruyter, A., Lonsdale, C. (2008). 'New Contractual Relationships in the Market for Agency Workers: The Case of the UK's National Health Service' British Journal of Industrial Relations 46(3) 389-412. 
Institute for Alcohol Studies (2014). 'Alcohol Fact Sheet' IAS, London.

Lillie, N. (2012). ' 'Subcontracting, posted migrants and labour market segmentation in Finland' British Journal of Industrial Relations 40(1) 87-103.

Lopes, A. and Hall, T. (2015). 'Organizing Migrant Workers: The Living Wage Campaign at the University of East London’ Industrial Relations Journal 46:3,208-221.

MacKenzie, R. and Forde, C. (2009). The Rhetoric of the "good worker" versus the realities of employer's use of and the experiences of migrant workers Work, Employment and Society 23(1) 142-160.

McAdams, R.H. and Nadler, J. (2008). 'Coordinating in the shadow of the law: Two contextualized tests of the focal point theory of legal compliance'. Law and Society Review, $42(4), 865-898$.

McCollum, D. and Findlay, A. (2015). Flexible Workers for Flexible Jobs? The Labour Market Function of A8 Migrant Labour in the UK Work, Employment and Society, 29(3) 427444.

McDowell L, Rootham, E. and Hardgrove, A. (2014). 'Precarious Work, Protest Masculinity and Communal Regulations: South Asian Young Men in Luton, UK' Work, Employment and Society 28(6) 847-864.

Narro, V. (2007). 'Finding Synergy between Law and Organizing: Experiences from the Streets of Los Angeles’ Fordham Urban Law Journal, 35(2) 339-372.

Narro, V. (2009). 'Si Se Puede!: Immigrant Workers and the Transformation of the LA Labour and Worker Centre Movements' Los Angeles Public Interest Law Journal, a project of community partners. $165-106$.

Office of Attorney General of California (2012). 'Attorney General Announces Settlement with Car Washes that Underpaid Workers and Violated Labour Laws' Press Release. http://ca.gov/news/press-release/attorney-general-kamala-d-harris-annouces, accessed March $14^{\text {th }}, 20015$.

Raess, D and Bourgoon, B. (2015). 'Flexible Working and Immigration in Europe' British Journal of Industrial Relations 53(1) 94-111.

Ram M, Edwards, P. and Jones, T. (2007). 'Staying Underground: Informal Work, Small Firms and Employment Regulation in the United Kingdom' Work and Occupations 34(3) $318: 344$

Ram M, Jones T, Edwards P, Kiselinchev A, Muchenje L and Woldersenbet, K. (2011). 'Engaging with Super-Diversity: New Migrant Businesses and the Research-Policy Nexus' International Small Business Journal 31(4) 337-356.

Rodriguez, N. (2004). “ "Workers Wanted”: Employer Recruitment of Immigrant Labour' Work and Occupations 31(4) 453-73. 
Rodriguez, E. (2007). " "The hidden side" of the new economy: on transnational migration, domestic work and unprecedented intimacy' Frontiers: A Journal of Women's Studies. 28(3) 60-83.

Rodriguez, E. (2004). 'We need your support, but the Struggle is Primarily Ours: On Representation, Migration and the Sans Papiers Movement, ESF Paris, November $12^{\text {th }}-15^{\text {th }}$, 2003' Feminist Review, 77. 152-156.

Srnicek, N. (2017). Platform Capitalism. Verso, London.

Srnicek, N. and Williams, A. (2015). Inventing the Future. Verso, London.

Skrivankova, K. (2010). Between decent work and forced labour: examining the continuum of exploitation. York, Joseph Rowntree Foundation.

Standing G (2014) The Precariat - The New Dangerous Class Bloomsbury, London.

Sunday Times (2016). 'Drivers Beware: Slaves Working at Car Washes' April 24 ${ }^{\text {th }}$.

Tapia, M. (2013). 'Marching to Different Tunes: Commitment and Culture as Mobilizing Mechanisms of Trade Unions and Community Organizations' British Journal of Industrial Relations 51(4) 666-688.

Tapia M, Turner L, and Roca-Servat D., (2014). Union Campaigns as Counter movements: "Best Practice" Cases from the United Kingdom, France and the United States in Adler L, Tabia M, and Turner L. (Eds) Mobilizing Against Inequality - Unions, Immigrant Workers and the Crisis of Capitalism. Ithaca, Cornell University Press.

Theodore N, Bernhardt A, DeFilippis J, Milkman R, Heckathorn D, Auer M, Gonzalez A, Narro V, Perelsjteum J, Polson D and Spiller, M. (2012). Under the Rader: Tracking The Violation of Labor Standards in Low Wage Industries in the US in Warhurst C, Carré F, Findlay P and Tilly, C. (Eds) Are Bad Jobs Inevitable? Trends, Determinants and Responses to Job Quality in the Twenty-First Century. London, Palgrave Macmillan.

W-A-S-H (2012). Workers Aligned for a Sustainable and Healthy New York. The Dirty Business of Cleaning NYC's Cars: Carwash Workers Face Low Pay. Offensive Conditions and Poor Treatment, credited to WASH but authored by Roca Servat D. Downloadable book/report available at http://www.washnewyork.org/files/car-wash-report.pdf accessed April 2nd 2015.

Wilkinson, M., Craig, G. and Gaus, A. (2010). Forced labour in the UK and the gang masters licensing authority. Hull, The Wilberforce Institute for the study of slavery and emancipation.

Williams, C. (2006). The Hidden Enterprise Culture: Entrepreneurship in the underground economy. Edward Elgar, Cheltenham.

Williams D (2009). Grounding the Regime of Precarious Employment Work and Occupations 36(3) 209-246.

Williams, C. and Windebank, J. (2001). 'Re-conceptualizing paid informal exchange: some lessons from English cities' Environment and Planning A 33, 121-40. 
Williams, C. and Windebank, J. (2002). 'The uneven geographies of informal economic activities: A case study of two British cities' Work, Employment and Society 16(2) 231-250.

Williams C (2014). 'Explaining Cross-National Variations in the Prevalence of Envelope Wages: Some Lessons from a 2013 Eurobarometer Survey' Industrial Relations Journal 45:6 524-542.

UK Petroleum Industry Association, (2015). Statistical Review available at http://ukpia.com downloaded January $31^{\text {st }}, 2016$

Wills J, Datta K, Evans Y, Herbert, J, May, J and McIlwaine, C. (2009). Global Cities at Work- New Migrant Divisions of Labour London, Pluto Press. 
